\title{
College English Translation Teaching Strategies under the Empathy Perspective
}

\author{
Wenxue YE \\ Yunnan Technology and Business University \\ Kunming,China
}

\begin{abstract}
Pragmatic empathy as the theoretical basis, combined with He Ziran's explanation for pragmatic empathy, from the pragmatic - linguistic and social - pragmatic to illustrate empathy applications in college English class. At the same time, combined with the practical experience of English teaching, this paper explores the revelation pragmatic empathy application for college English teaching.
\end{abstract}

Keywords- College English; translation teaching; Empathy Strategy

\section{INTRODUCTION}

He Ziran first put empathy to introduce the field of pragmatics, and made a pragmatic concept of transference. He believes that empathy on pragmatics embodied communicative other's focus. He pointed out that empathy on the pragmatics of verbal communication refers to the feelings of each other is interlinked, and they can conceive and understand each other's intentions, stand on each other's point of view to the encoding and decoding. Pragmatic Empathy focuses on both sides of the speaker to express emotion, focus as much as possible to narrow the psychological distance between them. From the standpoint of each communicator, Pragmatic Empathy can be divided into pragmatic - Language Empathy and social Pragmatic Empathy.

\section{A. Pragmatic - Language Empathy}

Pragmatic - Language Empathy refers to the speaker's use of language on the people to express their faith stance, attitude and intention, and the listener from the speaker's stand up to understand the speaker's discourse pragmatic meaning from obedient. For example, Chinese people greet each other when they meet on the road, they usually say: where are you going? Have you eaten yet? But when the Chinese people meet and talk to the British, the Chinese people will properly use their habits from the hearer's position? Expression says: How are you or It's a fine day, isn't it? This is because the speaker respect and apply the hearer's pragmatic practices, especially when speaker in the hearer's country.

\section{B. Social Pragmatic Empathy}

Social Pragmatic Empathy refers to verbal communication parties put themselves respect each other's thoughts and feelings and ideas, and they can have a mutual understanding of verbal communication in the process to promote communication smoothly. Social Pragmatic Empathy involves verbal communication and interpersonal social and cultural background, which respect each other's culture and customs. Social Pragmatic Empathy is in fact a cross-cultural empathy. When Chinese students use English, they are influenced by native culture and thinking, more or less according to the characteristics of Chinese culture to use words and make sentences. Good morning, teacher! Chinese students' courtesy and respect for the teacher's greeting expressions in class, they will use in English class Good morning, Teacher! Teacher greetings to the English-speaking countries, students often say Good morning, Sir / Mrs / Miss / Ms, only when the foreign teachers fully understand Chinese customs, habits and cultural differences, they can readily accept Good morning, Teacher!, indicating that foreign teachers focus on cross-cultural communication language Empathy, which is a common phenomenon called Romans.

\section{PRAGMATIC STRATEGIES AND THE USE OF EMPATHY}

\section{A. Equality Strategy}

Equality strategy refers to the speaker and listener in verbal communication is equal, the speaker himself as a member of the obedient people, and talk standing on the hearer's position, in order to achieve effective communication. This includes equality, equality of status and other social and cultural practices.

Equality of status: teachers should regard themselves as a member of the student, should not put themselves in superior position, and should try to shorten the psychological distance between students. For example: teachers who are good at using of equality policies will use personal pronouns change, such as the establishment and students agree. The most common way is: we are, we replace you, you, less imperative sentence. Generally students who entering vocational colleges are about 20 years old and now students have strong personality. The teacher can not just blindly command, command.

Experience and the situation are the same: the speaker based on the other side's situation, put himself in the same situation or the same experience. When student's score is poor, the teacher can take some of their own personal experiences to comfort students, encouraging students. It is easy to make students feel intimacy, also likely to have resonance. Do not scold and sighs in the classroom, when teachers and students have equal exchanges and interaction, students change from passive listening to active thinking, in order to truly reflect the status of the student body in the classroom teaching.

\section{B. Politeness strategies}

Do not use tendentious derogatory term when correct error, try to use positive language. Let's look at a conversation that frequently occurs between teachers and students. So what will result? From the student might have a sense of exclusion of the teacher, think that teacher do not enough respect him, making him publicly humiliated. But if 
teachers can acquire a certain pragmatic empathy strategy this way: Well, you first look at the combination with other students, I hope the next time you use something along all the classes. In this way, students may be very grateful, grateful to the teachers to maintain their self-esteem, so a good impression on the teacher must fold rise in class, and class efficiency will be greatly improved.

As much as possible express hope and wish even if you want to criticize, but also to avoid using direct, ironic language, the use of hope, hope euphemistic language like that. Because for some students, learn English well is like climb the peak, then they tend to have very subtle mind, the teacher's a little encouragement will induce the students a sense of accomplishment, certainly tend to protect students' interest, and a little bit harsh criticism is likely to destroy student's interest and motivation in the bud.

Instead of using ironic language, teacher should use humorous language. Educational methods should be adopted by teachers mainly positive, without prejudice to their selfesteem as precondition. Humor can be easily turned a tense atmosphere into easy, the opposite emotions effective mitigation. The irony will stimulate students' mentality and cause confrontation. For example, a teacher is indifferent to a sleepy student, almost after class, he wake up the students to answer questions, the students don't know the answer, and teacher quipped: you don't know the answer, and then you even sleep in class? The same situation, another teacher timely wake up the student, said: dream of coming Suzhou, is it fun? Wake up, the student embarrassed smile? Comparing the two, the effect is plain.

Timely use praise and encouragement language teach English would be more effective. Many students like to hear words of praise, unwilling to listen to criticism, then, so the English class teacher should be taken to encourage education, when a student make progress, you praise.

\section{Reasonable strategies}

That is sensible and reasonable. Require the speaker in the treatment of the hearer, their thoughts, attitudes was asked to consider the other side, the language environment to meet the prevailing situation. For example, even in the classroom, there will have unforeseen circumstances, students may suddenly uncomfortable lying on the table, then the teacher might say: You look very uncomfortable, leave to go to the infirmary or have a rest. Or sometimes after school when the teacher asked the students questions, but no matter what the teacher explained, students still do not understand, or stick to their answers, the teacher should not force the students agree with his answer.

\section{TRADITIONAL COLLEGE ENGLISH TRANSLATION TEACHING MODE'S MALPRACTICE AND REFORM INEVITABILITY}

Since the reform opening up, English education is highly valued in China, which is listed as a required course for university education. But years of teaching practice, college English translation teaching exist many drawbacks. Focus on theory but lack of practice, focus literary translation, ignore practical style translation, and decouple social needs. The traditional translation teaching usually spend most of their time to explain the translation theory, but focuses on literary translation, literary translation is taught methods and evaluation criteria, such as literal and free, domestication and alienation, functional equivalence and "faithfulness, expressiveness and elegance" and so on. But social and economic development these closely related to practical style translation technology and tourism is not enough, for which translation becomes widespread phenomena and laws are not taught, so students are deeply engaged in the practical translation powerless. Teachers dominant, students lack selflearning ability and creativity. The traditional translation classroom, teachers are the absolute authority, what materials to use, explains what kind of translation theory, translation exercises by doing what they decide, the students are passive recipients, lack of sense of participation and achievement, lack of energy and thus make the classroom dull. It focuses on correcting translations and single evaluation system. The traditional focus on the translation end product is students' works, the teachers spend a lot of time to modify the student's translation, the lack of understanding and guide the translation process, ignoring the students' the efforts and progress in the process, thus students in the face of absolute authority reference translation teachers tend to produce a deep frustration, and then to translate lessons produce psychological fear eventually lose interest in learning.

Based on the above analysis, the social economic development and translation talent training urgency make reform imperative traditional college English translation teaching mode. Must change the practice of re-theory of light practice at the same time involving the necessary theory and practice of literary translation, translation teaching but also to the needs of society as a starting point, the practical importance of translation practice, reposition the role of teachers and students, to enable students to more participate in and pay for the translation process-oriented, combining translation multifaceted assess student ability. All this can be to find a reasonable solution in the "translation workshop" Teaching mode.

\section{UNIVERSITY ENGLISH TRANSLATION TEACHING SITUATIONS}

Translation is an important skill for effective oral and written communication of information. Translation is an important part of teaching college English teaching, but a view of teaching and research in the field of translation ubiquitous: Teaching translation and foreign language teaching refers to the translation, lower requirements for translation, more suitable for professional courses and translation of other forms of foreign language teaching outside; and as a teaching, purpose translation teaching is a professional, high demands of its translation. There are several problems of college English translation teaching.

\section{A. Formal education curriculum leading to translation}

University English as public institutions of higher learning English courses, several reforms have reduced the number of hours, which resulted in the teaching process between teacher and student collaboration and interaction is 
limited, but also lack the necessary cooperation and communication between the students in the objective, plus not small class teaching, teachers can not modify each student's translation, so students can not get feedback from the teacher and not understand their own shortcomings and deficiencies, develop translation capability can not be guaranteed.

4.2 College English translation teaching still adhere to the traditional teaching model

Teacher's role is too centralized, in most cases, teachers explain techniques, and students just passively accept the translation given by teachers, and then compare their own answers. For if they mastered the translation skills, full of doubt. This teacher-centered teaching and to modify the student's grammar and wording of the error as a means to provide teachers with the reference translation course as the ultimate goal to enable students to have a greater inertia and dependence, which is not conducive to the students themselves formation and development capabilities.

4.3 lack of appropriate teaching materials

Although there are a number of national college English textbooks, but almost no National Commission compiled specifically for college English translation teaching materials. Even if you choose a good textbook, because the translation of the material can not be with the times, the student usually has very little exposure to foreign languages, so they can not translating and living together. Over time, students feel boring about translation exercises, so interest will soon disappear.

\section{B. Translational levels of college English teachers are not even}

Translation teaching not only requires teachers to master certain translation skills and some translation theory, but also to have some practical experience in translation. However, there are a limited number of foreign language teachers in their own language, they can not be in the classroom for students to practice effective translation guide.

\section{EMPATHY PRAGMATIC STRATEGIES AND ENGLISH TEACHING}

In China, students learned English mainly in the classroom, outside the classroom there is not much English language acquisition environment. Therefore, improving classroom teaching English is essential. Pragmatic Empathy strategies for teachers in teaching are how to properly use language effectively teaching students with emotional communication has far-reaching significance. Below I will introduce these three strategies specific use in teaching by example.

\section{A. Use equality strategy to eliminate the psychological distance with students}

Teachers in the teaching or talking with students should consider the proper use of language, to shorten the psychological distance between teachers and students, so that students feel warm, friendly and cordial in every possible way. For example, good use of equality policies and student exchange student, said: We are students, our main task is to learn. In fact, the teacher is the teacher, not the student, he just take equality strategy, put himself in the position of students, teachers fits this expression of Chinese linguists Liang Jingxiang "in speech communication, the speaker considered himself a member of the hearer community that mutual similarities between himself and the hearer".

\section{B. Use politeness strategies to avoid or mitigate conflicts of teachers and students}

Teachers should put themselves in the position of students, and try to maintain a positive face for students.Use reasonable strategy, proper use decent classroom English language,Classroom language teachers used in the classroom should be standardized, accurate, vivid and full of sense of humor. The method of discourse and language should with the students' understand ability. Skillful use of language is one of the basic factors of successful teaching.

Proper use of reasonable strategies, use decent language for students' error correction, hints, help maintain the enthusiasms of students, in this way can teachers and students maintain a good relationship. Students in the classroom greatly affected by the mood of teachers, excellent teachers should know how to control the student's emotional reasonably by using classroom language well.

\section{CONCLUSIONS}

In short, in the teaching process, teachers are the communicators language information, the purpose of English teaching is enabling students to use English decent communication, therefore, teachers should make full use of pragmatic empathy theory, highlighting student-centered teaching, the students in the classroom as a core, consciously use the Pragmatic - empathy and social - Pragmatic Empathy two aspects for classroom teaching, this will effectively improve English classroom teaching.

\section{References}

[1] Li Jing, Xiong Yonghong. Pragmatic Empathy Strategy in English Teaching [J] Hunan Institute of Humanities Science and Technology, 2009, 06: 121-123.

[2] Deng Hongchun. Intercultural Perspective College English Translation Teaching [J] Shanxi Radio \& TV University, 2011,06: 72-73.

[3] Huang Xianghui. Pragmatic Empathy strategy in the hotel scene in English [J]. Science and Technology Information, 2011, 31: 354-355.

[4] Huang Ying. Language Applies Empathy Strategies Case Study of English Teaching in Higher Vocational Colleges SPSS Analysis [J] Changsha Aeronautical Vocational and Technical College, 2012, 02: 16-21.

[5] Yu Bin. College English Translation Teaching an Analysis of the Next Linguistics [J] intelligence, 2014, 22: 186.

[6] Wang Xiaoyan. Chunk Perspective College English Translation Teaching Strategies Study [J] overseas English, 2014,23: 50-51. 